\title{
Impacts of Fluorine-treatment on E-mode AIGaN/GaN MOS-HEMTs
}

\author{
X. Sun ${ }^{1 *}$, Y. Zhang ${ }^{2}$, K. S. Chang-Liao ${ }^{3}$ T. Palacios ${ }^{2}$, and T. P. Ma ${ }^{1}$ \\ ${ }^{1}$ Yale Univ., CT, USA ${ }^{2}$ Massachusetts Institute of Technology (MIT), MA, USA ${ }^{3}$ National Tsing Hua Univ., Taiwan \\ Phone: +1 203-980-4789, ${ }^{*}$ E-mail: xiao.sun@yale.edu
}

\begin{abstract}
The impact of fluorine treatment on $\mathrm{AlGaN} / \mathrm{GaN}$ MOS-HEMTs has been investigated. Fluorine was found to suppress pre-existing traps in MOS-HEMT, which improves the off-state at high temperatures. Fluorine doping and associated etching, however, also generates slow border traps and fast interface states that degrade the MOS-HEMT performance. Multi-faceted mechanisms for drain current degradation due to F-doping and gate-recess-etch have been investigated in enhancement-mode MOS-HEMTs.
\end{abstract}

\section{Introduction}

GaN based MOS-HEMTs are emerging devices for high power and RF applications. Gate-recess etch and fluorine (F) doping are approaches commonly taken to achieve enhancement-mode (E-mode) operation $[1,2]$. These technologies, however, tend to result in $\mathrm{V}_{\text {th }}$ instability and drain current $\left(\mathrm{I}_{\mathrm{d}}\right)$ degradation in HEMTs [3-7], which could be attributed to F-induced bulk and interfacial traps. In an MOS-HEMT, the related scenario is more complex, because the inserted gate dielectric could weaken the screening effect of gate meatal and introduce traps in bulk oxides or at the oxide/barrier-layer interface [8]. In this work, we investigated multifaceted impacts of F-doping and associated etching on E-mode MOS-HEMTs over a wide range of fluorine doses.

\section{Experimental}

HEMT structures were fabricated on a commercial GaN-on-silicon wafer (Fig.1). To obtain E-mode behavior, the AlGaN (Al: 26\%) barrier in the gated region was treated by $\mathrm{CF}_{4}$ plasma at an $\mathrm{ECR} / \mathrm{RF}$ power of $150 \mathrm{~W} / 20 \mathrm{~W}$ for varying intervals of time (TEM in Fig.1). More experimental details can be found in [9]. SIMS study shows the peak of F-concentration at the top AlGaN surface (Fig.2). MOS-HEMT devices were also fabricated by depositing ALD- $\mathrm{Al}_{2} \mathrm{O}_{3}$ immediately after F-treatment, during which $\mathrm{F}$ was driven into $\mathrm{Al}_{2} \mathrm{O}_{3}$ from the $\mathrm{AlGaN}$ underneath. $\mathrm{F}$ treatment can effectively increase $\mathrm{V}_{\text {th }}$ up to $\sim 4 \mathrm{~V}$ for $\mathrm{CF}_{4}$ treatments of $\sim 120 \mathrm{~s}$, as shown in Fig. 3. In Fig. 4, the gate stack thickness decreases with $\mathrm{CF}_{4}$ time, indicating that $\mathrm{F}$ also etches $\mathrm{AlGaN}$ barrier layer during the $\mathrm{CF}_{4}$ plasma treatment. The resulting thinning of $\mathrm{AlGaN}$, i.e., gate-recess-etch, along with negative charges induced by $\mathrm{F}$ ions can effectively increase $\mathrm{V}_{\text {th }}$. Additional $\mathrm{CF}_{4}$ plasma, however, caused serious degradation of on- and off- currents $\left(\mathrm{I}_{\mathrm{on}}, \mathrm{I}_{\mathrm{off}}\right)$ as shown in Fig. 3 and elsewhere $[5,6]$.

\section{F-passivation of traps in MOS-HEMT}

In MOS-HEMTs, traps exist at the oxide/AlGaN interface and in the gate oxide [8-11]. In this work we have found that these traps appear in the MOS-HEMT with $\mathrm{Al}_{2} \mathrm{O}_{3}$ as gate

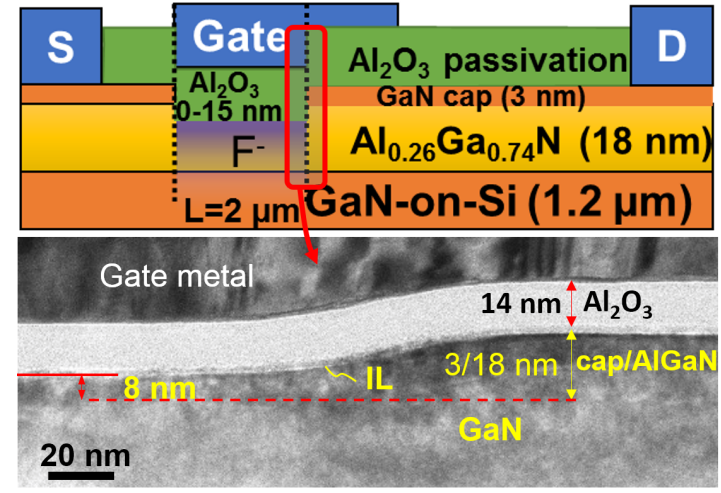

Fig. 1 Schematic and TEM views of MOS-HEMT device studied in this work; The TEM shows a device with $8 \mathrm{~nm}$ of $\mathrm{AlGaN}$ and $14 \mathrm{~nm} \mathrm{Al}_{2} \mathrm{O}_{3}$ on top. treated by $\mathrm{CF}_{4}$ for $120 \mathrm{~s}$.

oxide, and are detrimental to the off-state at high temperatures. Fig. 5 shows that, although the hysteresis and $\mathrm{I}_{\text {off }}$ are small for depletion-mode MOS-HEMTs at $300 \mathrm{~K}$, at higher temperatures they increase drastically. The Subthreshold Swing (SS) at different temperatures reveals that while more traps can respond to $\mathrm{dc}-\mathrm{V}_{\mathrm{g}}$ sweep at higher temperatures, they are positively charged above $\mathrm{E}_{\mathrm{F}}$,

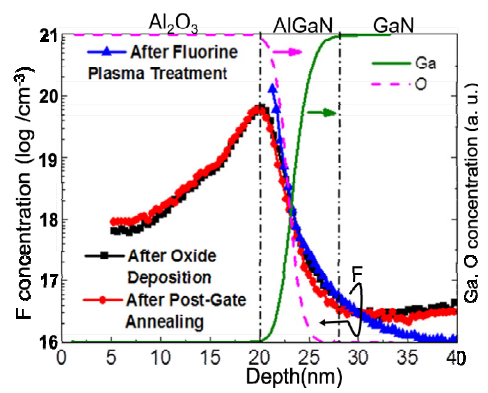

Fig.2 SIMS indicates that $\mathrm{F}$ concentration peaks at the $\mathrm{AlGaN}$ upper surface $\left(\mathrm{Al}_{2} \mathrm{O}_{3} / \mathrm{AlGaN}\right)$. $\mathrm{F}$ diffuses into the $\mathrm{Al}_{2} \mathrm{O}_{3}$ during the ALD process (after [9]).

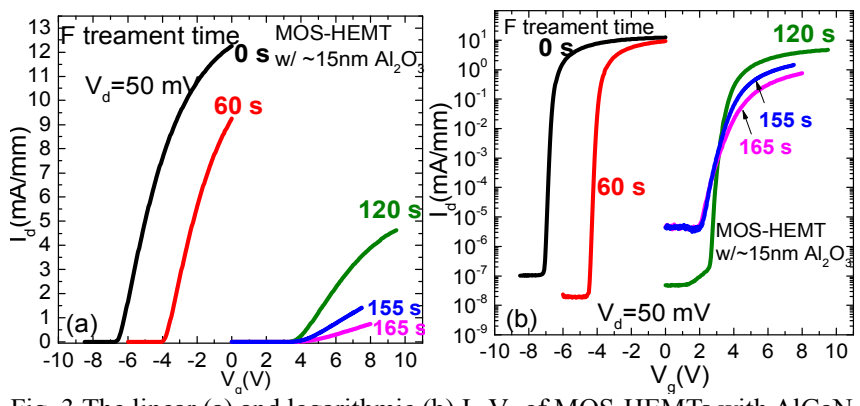

Fig. 3 The linear (a) and logarithmic (b) $\mathrm{I}_{\mathrm{d}}-\mathrm{V}_{\mathrm{g}}$ of MOS-HEMTs with AlGaN treated by $\mathrm{CF}_{4}$ for time intervals from $0 \mathrm{~s}$ to $165 \mathrm{~s}$. $\mathrm{I}_{\mathrm{on}}$ and $\mathrm{SS}$ degradation is observed after high $\mathrm{F}$ doses. 


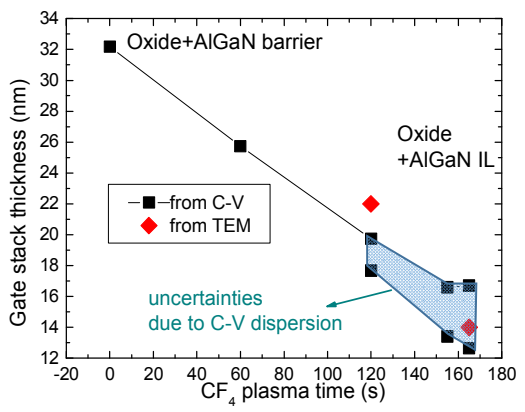

Fig.4 Total gate stack thickness (including $\mathrm{Al}_{2} \mathrm{O}_{3}$ and $\mathrm{AlGaN}$ layers) after $\mathrm{CF}_{4}$ plasma treatment of varying intervals of time, as extracted from $1 \mathrm{MHz}$ $\mathrm{C}-\mathrm{V}(\varepsilon \sim 10)$ and TEM.

resulting in a negative shift of $\mathrm{V}_{\text {th }}$ and thus a high $\mathrm{I}_{\text {off }}$, i.e., difficult turn-off. It is observed that some deep-level traps-"fixed" positive charges commonly found in GaN MOS-HEMT [10,11] — could also emit/capture electrons in the $\mathrm{V}_{\mathrm{g}}$ operation range under high temperatures. For HEMT devices, that has no gate oxides, such degradation does not exist, as shown in the inset of Fig. 5b, proving that the traps are introduced by the $\mathrm{Al}_{2} \mathrm{O}_{3}$, including those in $\mathrm{Al}_{2} \mathrm{O}_{3}$ bulk or at $\mathrm{Al}_{2} \mathrm{O}_{3} / \mathrm{AlGaN}$ interface. Notably, the F-plasma treatment, even with a light dose that is not sufficient to achieve E-mode, is effective in passivating these traps. In Fig. 5b, the MOS-HEMT with $60 \mathrm{~s}$ of $\mathrm{CF}_{4}$-treated AlGaN shows little hysteresis and well-behaved $\mathrm{I}_{\text {off }}$ even at $540 \mathrm{~K}$, in strong contrast to the untreated $\mathrm{AlGaN}$. Given that $\mathrm{F}$ plasma treatment has been reported to be stable in $\mathrm{AlGaN}$ at least up to $800{ }^{\circ} \mathrm{C}$ [12], fluorine doping could be a beneficial process for good high-temperature characteristics in $\mathrm{GaN}$ MOS-HEMT.
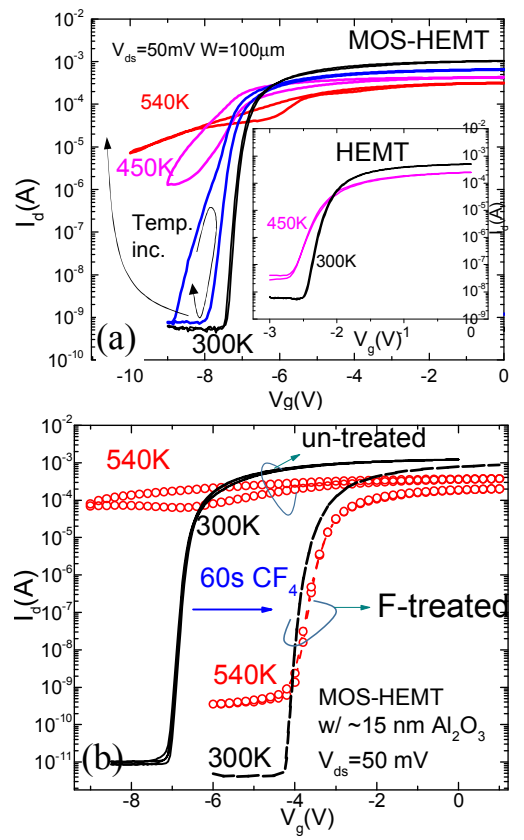

Fig.5 (a) degradation in the $\log \mathrm{I}_{\mathrm{d}}-\mathrm{V}_{\mathrm{g}}$ curves (including hystereses) with increasing temperatures from $300 \mathrm{~K}$ to $540 \mathrm{~K}$ in the untreated $\mathrm{Al}_{2} \mathrm{O}_{3}$-MOS-HEMT. The inset shows the untreated HEMT device without $\mathrm{Al}_{2} \mathrm{O}_{3}$. (b) $\log \mathrm{I}_{\mathrm{d}}-\mathrm{V}_{\mathrm{g}}$ curves (including hystereses) for the untreated- and the $60 \mathrm{~s}-\mathrm{CF}_{4}$ treated $\mathrm{Al}_{2} \mathrm{O}_{3}-\mathrm{MOS}-\mathrm{HEMTs}$ at $300 \mathrm{~K}$ and $540 \mathrm{~K}$.

\section{Slow border traps in AlGaN}

We adapted the ac-transconductance $\left(g_{m}\right)$ method to examine possible slow traps in AlGaN generated by F-treatment. In the $a c-g_{m}$ method, under small $a c-V_{g}$, the occupation of traps in gate stacks fluctuates due to capture and emission of carriers. By modulating the $a c-V_{g}$ frequencies, $a c-g_{m}$ is able to reflect traps with varying time constant $(\tau)$. Unlike conventional gate admittance methods involving $a c$ gate currents (such as $\mathrm{C}-\mathrm{V}$ and $\mathrm{G}-\mathrm{V}$ ), the $a c-g_{m}$ method probes much larger drain currents with much higher signal-to-noise ratios at low frequencies (down to $10 \mathrm{mHz}$ ), and hence is able to probe traps with longer $\tau(100 \mu s-100 s)$. More details of the method can be found in [13, 14].

To focus on the traps in F-treated AlGaN, AlGaN/GaN HEMTs without gate oxides were tested. The results show that slow traps are introduced by F-treatment in AlGaN. In Fig. 6, for both the untreated and F-treated devices, $a c-g_{m}$ shows little frequency dispersion at $300 \mathrm{~K}$. But the F-treated one shows a large positive frequency dispersion at $540 \mathrm{~K}$, suggesting F-induced traps capture channel electrons through inelastic tunneling. For untreated device, the frequency dispersion is negligible at $540 \mathrm{~K}$ (inset of Fig. 6b). Fig. 7 shows the normalized $a c-g_{m}$ vs. frequency at different temperatures. The corresponding Arrhenius plots show an activation energy $E_{a}=E_{T}-E_{F}$ of $0.3 \mathrm{eV}$ for the as-deposited, and $E_{a}=0.75 \mathrm{eV}$ after $400^{\circ} \mathrm{C}$ annealing (Fig. 8), consistent with theories that annealing is critical for fluorine to form stable trapping centers [15-17]. Because the traps have an $E_{a}$ larger than the $\mathrm{AlGaN} / \mathrm{GaN}$ conduction band offset, they must not be at the interface, but instead should be in AlGaN as border traps, as in the band diagram shown in Fig. 9.

F-induced slow traps in $\mathrm{AlGaN}$ also result in trap-assisted-tunneling (TAT) in HEMT devices, as evidenced by the $a c-g_{m}$ measurements. In Fig. 7c, a negative frequency dispersion appears in addition to the positive one, as the traps exchange electrons with the gate in addition to the channel [8] (Fig. 9), resulting in TAT in the gate stack of HEMTs. In MOS-HEMTs, however, the gate oxide suppresses TAT, so this $a c-g_{m}$ feature is missing. As such, F-induced traps deep in AlGaN, with higher densities (Fig. 2), result in Fermi-level (FL) pinning by trapping electrons without detrapping them to the gate. For example, in Fig. 10, the dc- $\mathrm{I}_{\mathrm{d}}$ degradation after $10 \mathrm{~s}$ of additional F-plasma in MOS-HEMTs can be simulated well by considering the FL pinning induced by a trap band (the inset of Fig. 10a).
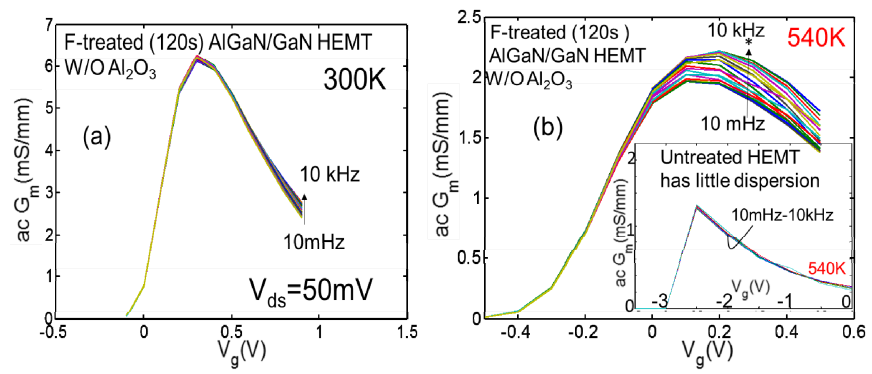

Fig. $6 \mathrm{AC}-g_{m}$ Vs. $\mathrm{V}_{\mathrm{g}}$ at ac- $\mathrm{V}_{\mathrm{g}}$ frequencies from $10 \mathrm{mHz}$ to $10 \mathrm{k} \mathrm{Hz}$ at (a) $300 \mathrm{~K}$ and (b) $540 \mathrm{~K}$ for $\mathrm{AlGaN} / \mathrm{GaN}$ HEMT with $120 \mathrm{~s} \mathrm{CF}_{4}$ treatment. The inset in (b) shows the $a c-g_{m}$ for the sample without F-treatement. * In Fig. 6(b), the frequency dependence is not completley monotonic. (see Fig. 7c) 

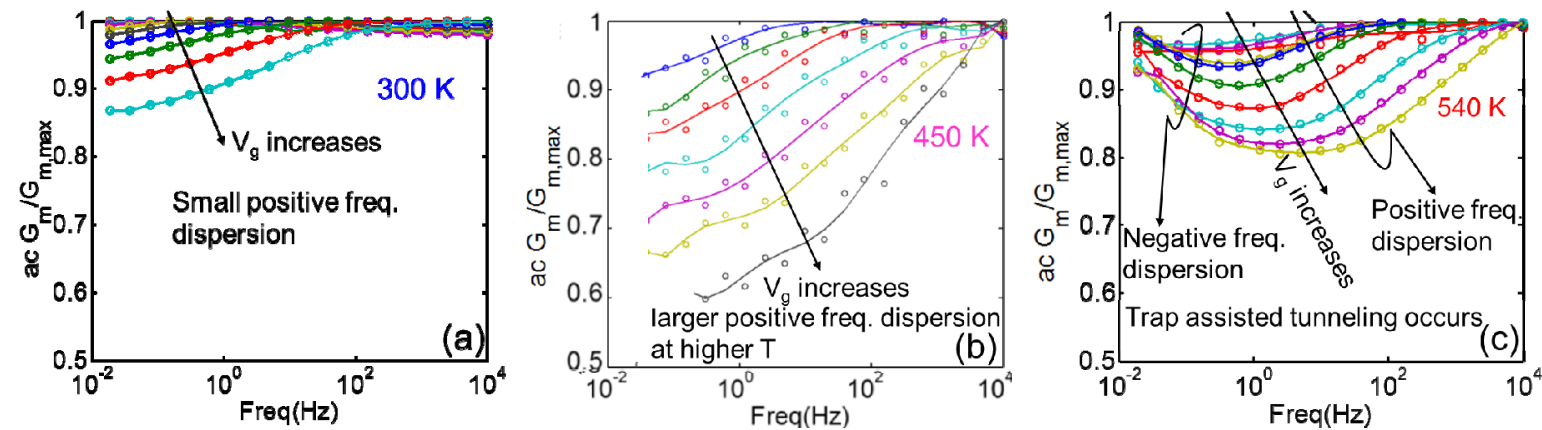

Fig. 7 Normalized $a c-g_{m}$ vs. ac- $\mathrm{v}_{\mathrm{g}}$ frequency for the AlGaN/GaN HEMT devices after $400^{\circ} \mathrm{C}$ annealing at (a) $300 \mathrm{~K}$, (b) $450 \mathrm{~K}$, and (c) $540 \mathrm{~K}$. Fig. 7 (c) shows that a negative frequency dispersion (the recovery of the positive frequency dispersion) appears in the $540 \mathrm{~K}$-annealed sample below $\sim 1 \mathrm{~Hz}$.

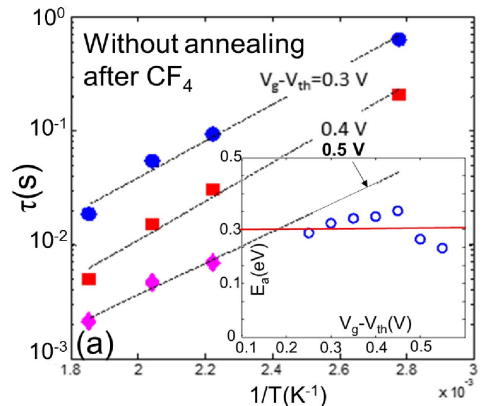

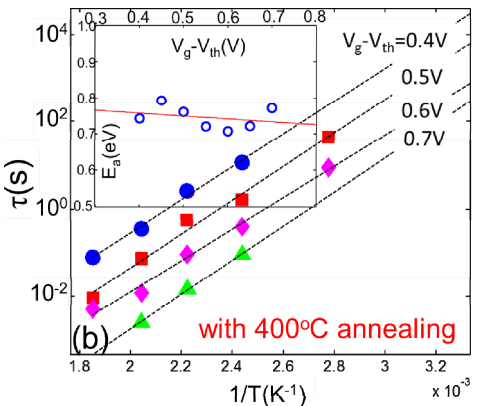

$1 / \mathrm{T}\left(\mathrm{K}^{-1}\right)$

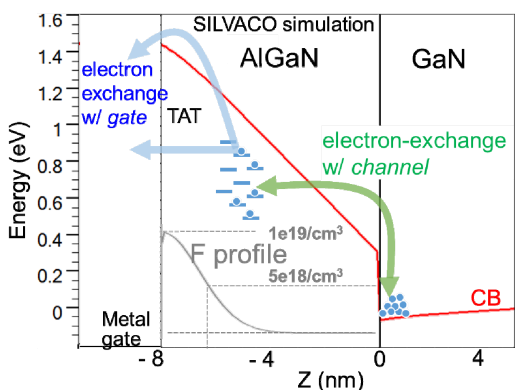

Fig. 9 Conduction band of the $\mathrm{AlGaN} / \mathrm{GaN}$ gate stack in a HEMT simulated by SILVACO, resulting from inputing a $\mathrm{F}$ doping profile (all ionized) shown in the inset. treatment. In the y axis, $\tau=1 / f$, and $\mathrm{f}$ is the frequency where ac- $\mathrm{g}_{\mathrm{m}}$ decreases by half of the maximum measured degradation in the frequency scope. Each inset shows $E_{a} v s$. dc gate overdrive $V_{g}-V_{\text {th }}$.
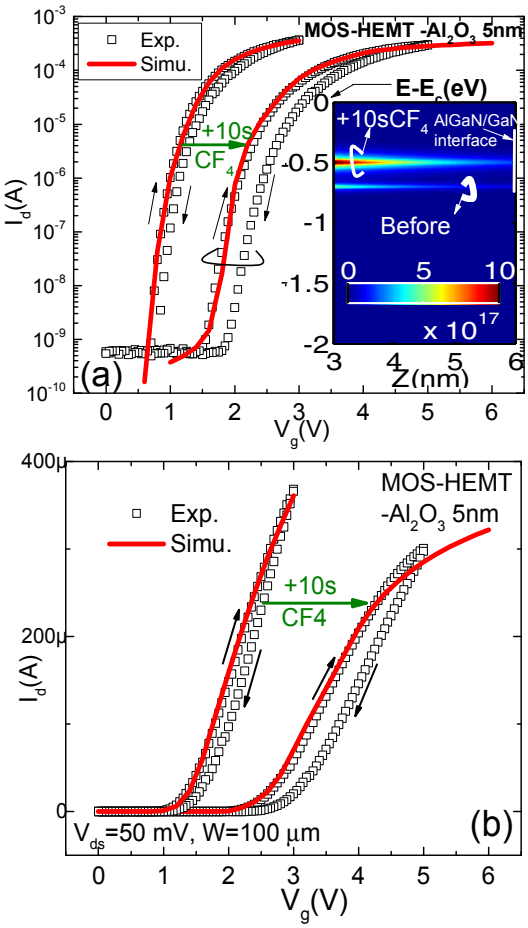

Fig. 10 Simulated and experimental $I_{d}-V_{g}$ (with hystereses) in (a) linear and(b) log scale for two MOS-HEMTs $\left(5 \mathrm{~nm} \mathrm{Al}_{2} \mathrm{O}_{3}\right)$ having 10 s difference in $\mathrm{CF}_{4}$ treatment time interval. The inset of (a) shows the trap profile input to SIVACO: Trap density (contour) vs. Energy $\left(E_{-} E_{c}\right)$ and Distance $(Z)$ from the $\mathrm{Al}_{2} \mathrm{O}_{3} / \mathrm{AlGaN}(\sim 6 \mathrm{~nm})$ interface

\section{Fast interface states at GaN Interface}

In additional to slow traps, $\mathrm{F}$ plasma also induces fast interface states on $\mathrm{GaN}$ in the presence of an AlGaN blocking layer. $\mathrm{C}-\mathrm{V}$ and $\mathrm{G}-\mathrm{V}$ can probe such fast interface states in the subthreshold region when the trap time constants are longer with lower carrier density [18]. In Fig. 11, a large C-V dispersion appears after the MOS-HEMT is turned into E-mode by fluorine, when $\mathrm{AlGaN}$ is still relatively thick, e.g., $8 \mathrm{~nm}$ after $120 \mathrm{~s}$ of $\mathrm{CF}_{4}$, as shown by TEM in Fig. 1. In Fig. 12 , the frequency of the $\mathrm{G}_{\mathrm{p}} / \omega$ peak from the $\mathrm{G}-\mathrm{V}$ measurements reflects FL movement under $\mathrm{V}_{\mathrm{g}}$, and the value thereof reflects the interface state density $\left(\mathrm{D}_{\mathrm{it}}\right)$. A $60 \mathrm{~s} \mathrm{~F}$ plasma treatment can reduce $D_{i t}$ from $10^{11}$ to $10^{10} / \mathrm{cm}^{2} / \mathrm{eV}$, indicating that light-dose $\mathrm{F}$ could passivate the pre-existing traps at/near the GaN interface. However, further treatment to $120 \mathrm{~s}$ increases $D_{\text {it }}$ to $10^{11} / \mathrm{cm}^{2} / \mathrm{eV}$, possibly due to fluorine accumulation at the $\mathrm{AlGaN} / \mathrm{GaN}$ interface. Finally, $165 \mathrm{~s}$ increases $D_{\text {it }}$ to $10^{12} / \mathrm{cm}^{2} / \mathrm{eV}$, consistent with the $D_{\text {it }}$ level of the $\mathrm{Al}_{2} \mathrm{O}_{3} / \mathrm{GaN}$ interface in $\mathrm{GaN}$ MOSFETs [19]. Indeed, TEM reveals that at $165 \mathrm{~s}, \mathrm{~F}$ treatment has etched all the $\mathrm{AlGaN}$ and reached the $\mathrm{GaN}$, yielding an $\mathrm{Al}_{2} \mathrm{O}_{3} / \mathrm{GaN}$ interface (Fig. 13). Plasma over-etch can also damage the GaN surface [20].

\section{$I_{d}$ degradation mechanism in F-treated MOS-HEMTs}

$I_{d}$ degradation in F-treated MOS-HEMTs (Fig. 3) results from both mobility $(\mu)$ drop and FL pinning. In Fig. 14, $I_{d}$ can be mostly recovered by $50-n s$ pulsed $I_{d}-V_{g}$ measurement for medium F-dose (120 s), but can only be partly mitigated for heavy F-dose (165 s), partially because the time constants of generated interfaces states in the later are much shorter than $50 \mathrm{~ns}$. 

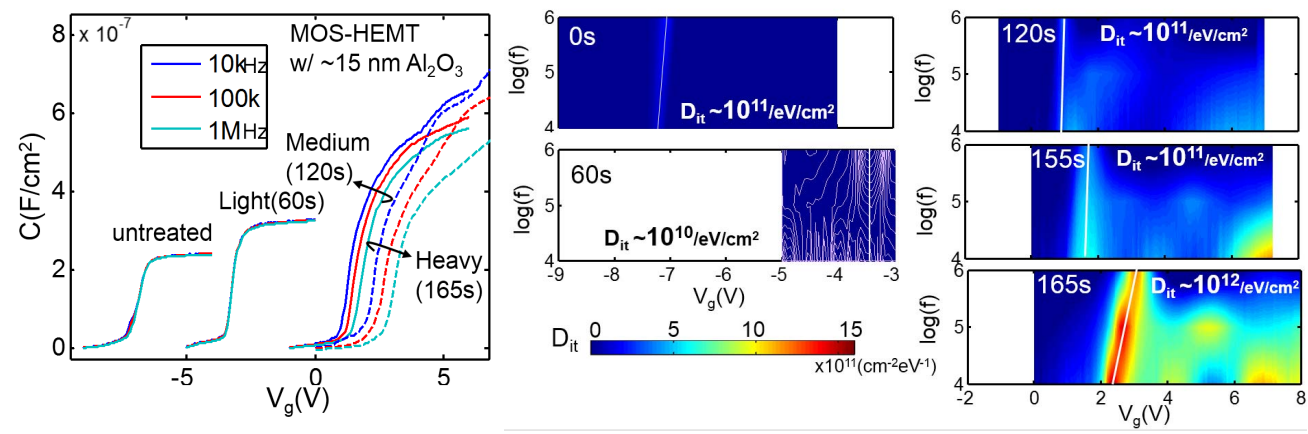

Fig. 11(left) C-V dispersions from $10 \mathrm{kHz}$ to $1 \mathrm{MHz}$ of MOS-HEMTs $\mathrm{W} / 215 \mathrm{~nm} \quad \mathrm{Al}_{2} \mathrm{O}_{3}$ that received F-treatment with time intervals from $0 \mathrm{~s}$ to $165 \mathrm{~s}$

Fig. 12(right) $\mathrm{G}_{\mathrm{p}} / \omega$ contour vs. gate frequency and $\mathrm{dc}-\mathrm{V}_{\mathrm{g}}$ for MOS-HEMTs w/ $\sim 15 \mathrm{~nm} \mathrm{Al}_{2} \mathrm{O}_{3}$ that received $\mathrm{CF}_{4}$ for different time intervals. The peaks of $\mathrm{G}_{\mathrm{p}} / \omega$ in subthreshold region are traced by white lines. The value of $\mathrm{Gp} / \omega$ is transformed to $\mathrm{D}_{\text {it }}$ based on the
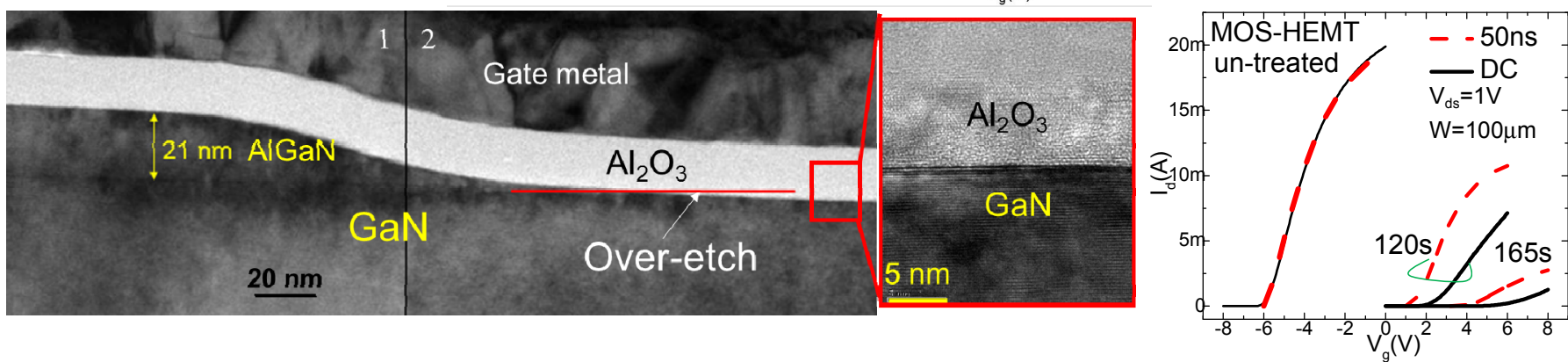

Fig. 13 A cross sectional view of $165 \mathrm{~s}-\mathrm{CF}_{4}$ treated MOS-HEMT by TEM. The frame on the Fig. 14 DC and pulsed $\mathrm{I}_{\mathrm{d}}-\mathrm{V}_{\mathrm{g}}(50 \mathrm{~ns})$ for MOS-HEMTs $\mathrm{w} / \sim 15 \mathrm{~nm}$ right shows an enlarged view of the resulting $\mathrm{Al}_{2} \mathrm{O}_{3} / \mathrm{GaN}$ interface by F-plasma over-etch. $\mathrm{Al}_{2} \mathrm{O}_{3}$ that received different $\mathrm{CF}_{4}$ treatment time intervals

On the other hand, Fig. 15 shows the measured $\mu$ and $V_{\text {th }}$ as functions of $\mathrm{F}$ plasma time for HEMTs and MOS-HEMTs. Unlike HEMTs, $\mu$ degrades dramatically in MOS-HEMTs with $\sim 15 \mathrm{~nm} \mathrm{Al}_{2} \mathrm{O}_{3}$, especially for the E-mode. The mechanisms of $\mathrm{I}_{d}$ degradation after $\mathrm{F}$ treatment are summarized below, in the order from low-dose to high-dose: (1) the thinning of $\mathrm{AlGaN}$ by $\mathrm{F}$ etching reduces $2 \mathrm{DEG}$ density and $\mu$; (2) F generates border traps in AlGaN, resulting in FL pinning; (3) with a few nm of AlGaN left, $\mathrm{F}$ can generate interface states at AlGaN/GaN, resulting in stronger FL pinning and $\mu$ drop; (4) after AlGaN being completely etched out, plasma damage and a high-concentration of $\mathrm{F}$ in the GaN channel could degrade $\mu$ significantly by scattering (Fig. 15). Compared to MOS-HEMTs, HEMTs show little degradation in $\mu$ after $120 \mathrm{~s} \mathrm{~F}$ plasma treatment, due to TAT and gate screening of trapped charges, but at the cost of low $\mathrm{V}_{\text {th }}$. A tradeoff therefore exists between $V_{\text {th }}$ and $I_{\text {on }}$ for these devices that use $\mathrm{F}$ implantation and/or gate-recess to achieve E-mode.

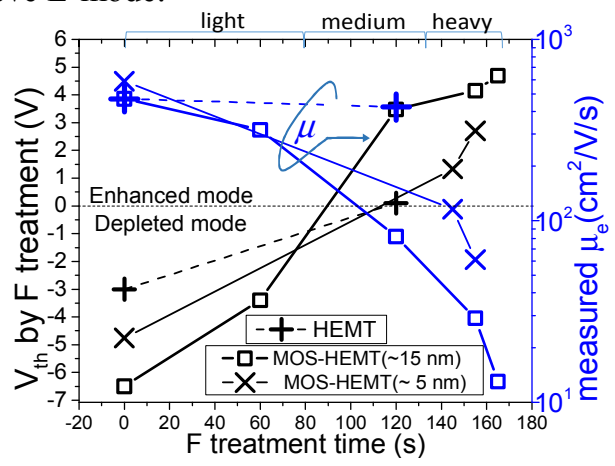

Fig. $15 \mathrm{~V}_{\text {th }}$ and measured peak mobility vs. $\mathrm{CF}_{4}$ treatment time interval for HEMT and MOS-HEMTs with $\sim 5 \mathrm{~nm}$ and $\sim 15 \mathrm{~nm} \mathrm{Al}_{2} \mathrm{O}_{3}$.

\section{Summary}

In summary, fluorine treatment enhanced SS and $\mathrm{I}_{\text {off }}$ of MOS-HEMT at high temperatures, by passivating traps contained in gate stacks of GaN MOS-HEMT devices. More Fluorine treatment, however, results in border traps in $\mathrm{AlGaN}$ with $E_{a} \sim 0.75 \mathrm{eV}$, and interface states at AlGaN/GaN, degrading $I_{\text {on }}$ through pinning $F L$ and reducing mobility. Extremely low mobility can occur due to over-etch-induced $\mathrm{GaN}$ surface damage and high fluorine impurity concentrations within the channel.

\section{Acknowledgement}

This work is partially sponsored by ONR DEFINE MURI, and DTRA under HDTRA 1-10-1-0042.

\section{Reference}

[1] Y. Cai et al IEEE Tran. Elec. Dev., 53, p.2207, 2006

[2] T.Oka et al IEEE Elec. Dev. Lett., 29, p.668, 2008

[3]C. -Y. Ma, et al IEDM 2010, p. 476

[4]C.-W. Yi, et al IEDM 2007, p. 389

[5]A. Basu et al J. Vacuum Sci. Tech. B 25, p. 2607, 2007

[6] B. K. Li, et al Appl. Phys. Lett., 92, 082105, 2008.

[7] D. Bisi et al ESSDERC 2013, p.61

[8] X. Sun et al, Appl. Phys. Lett., 102, 103504, 2013

[9] Y. Zhang et al Appl. Phys. Lett. 103, 033524 (2013)

[10] J. P. Ibbetson et al, Appl. Phys. Lett. 77, 250, 2000

[11] S. Ganguly, et al Appl. Phys. Lett. 99, 193504, 2011

[12] M. J. Wang, et al J. Appl. Phys. 105, 083519, 2009

[13] X. Sun IEEE Elec. Dev. Lett. 33, p.438, 2012

[14] X. Sun et al IEDM 2012, 19.4.1

[15] K. Chen et al, IEDM 2011, p. 465

[16] A. Basua et al, J. Appl. Phys. 105, 033705, 2009

[17] M. J. Wang et al, Appl. Phys. Lett. 94, 061910, 2009

[[18] E. H. Nicollian and J. R. Brews, MOS Physics and Technology, Wiley,New York, 1982

[19] Y. Q. Wu et al, Appl. Phys. Lett., 90, 143504, 2007

[20] T. J. Anderson et al, J. Elec. Material., 39, p. 478, 2010 